\title{
Deposition of Zinc Oxide thin film layer with the help of modified sputtering system
}

\author{
S.A. Fomchenkov ${ }^{1,2}$, S.D. Poletaev ${ }^{1,2}$ \\ ${ }^{1}$ Image Processing Systems Institute - Branch of the Federal Scientific Research Centre "Crystallography and Photonics" of Russian Academy of Sciences, 151 \\ Molodogvardeyskaya st., 443001, Samara, Russia \\ ${ }^{2}$ Samara National Research University, 34 Moskovskoe Shosse, 443086, Samara, Russia
}

\begin{abstract}
The process of magnetron sputtering of dielectric zinc oxide $(\mathrm{ZnO})$ films at a constant current source, was studied. It is demonstrated that this method of dielectric films deposition makes it possible to obtain high-quality coatings and layers that meet the requirements for creating multilayer diffractive optical elements.
\end{abstract}

Keywords: magnetron sputtering; thin films; diffraction optical elements; Zinc Oxide

\section{Introduction}

In recent years, the development of diffractive optical elements (DOE) have attracted the researchers due to the prospects of their use in optical signal and image processing systems, including in computational optics. In addition to the traditional use of DOE as spectral selectors, a significant number of DOE types have been developed so far, allowing many other functions such as multiplication and beam formation, optical signal distribution through processing channels, wave front formation, etc [1-3]. As a rule, the optical characteristics of such multilayer elements depend on many factors such as their structure, materials used and their refractive indices, the order and ratio of layer thicknesses and micro-relief, internal or surface [4,5].

The basis of such elements are optically transparent in the visible or infrared range, dielectric alternating films deposited on an optical quality substrate, for example, quartz. Various methods for the deposition of films can be used to create such structures: vacuum thermal deposition [6,7], electron-beam sputtering, and many others. But the creation of optical elements requires high quality and accuracy of the results. Therefore, the most preferred method is magnetron sputtering. This method allows the film to be sprayed at a high speed, with a low pressure of the working gas in the chamber, which allows obtaining very pure structures [8].

In this paper, we investigated the possibility of obtaining such structures using a magnetron sputtering installation with a constant current source "Caroline D12A", modernized for the purpose of sputtering dielectric targets.

\section{The object of the study (Model, Process, Device, Sample preparation etc.)}

The installation of magnetron sputtering "Caroline D12A" is designed for the deposition of conductive films, so it has a constant current source. The unit is equipped with four positions for the installation of targets, which allows the deposition of four different materials in one operating cycle. This embodiment does not permit the dispersion of dielectric films since charge accumulation occurs on the dielectric target, which contradicts the principle of magnetron sputtering. And the power supply to the magnetron results in the start-up and quick stopping of the spraying in a very short time. To solve this problem, the power supply was replaced by a high-frequency generator with an operating frequency of $13.56 \mathrm{MHz}$ and a maximum output power of $1 \mathrm{~kW}$. This solution allows us to accumulate a charge for one half-period of the signal being supplied and to take it off during the second half-period.

The biggest challenge during the modernization of Caroline D12 A was the development and optimization of the matching device between the generator and the magnetron. As a result of the work done, the optimal ranges and ratios of the components of the matching device, namely a tunable coil and a tunable capacitor, were selected. This allowed us to achieve an optimal alignment with allowance for unrecoverable losses (15\%).

In this work, $\mathrm{ZnO}$ target was used for the demonstration of the sputtering process. The refractive index of the deposited layer was measured with the help of ellipsometer as shown in Fig. 1.

In the course of the work, the optimal parameters for the deposition of a zinc oxide film on a quartz substrate were obtained. The power supplied from the signal generator $\mathrm{P}=500 \mathrm{~W}$, an argon flow rate $\mathrm{Q}(\mathrm{Ar})=2.01 / \mathrm{h}, \mathrm{Q}(\mathrm{O} 2)=0.7 \mathrm{l} / \mathrm{h}$, the residual pressure in the chamber $\mathrm{p}=5 \times 10^{-4} \mathrm{~Pa}$, substrate heating temperature was $\mathrm{t}=120^{\circ} \mathrm{C}$, the drum rotation speed $\mathrm{V}=11 \mathrm{RPM}$. The distance from the target to the substrate was about $20 \mathrm{~cm}$.

As a result, high-quality thin film of zinc oxide was obtained on quartz substrate. The scratch test indicated that the adhesion of the film to the substrate was high. The optical and physical properties of the thin film was measured with the help of films "Ellipsometer M2000DI".Consequently, the deposition rate was $10 \mathrm{~nm} / \mathrm{min}$.

For optical applications, the layers should be homogenous over the entire surface of the substrate. To study these properties, the surface of the film was examined using a Zygo NewView 7300 white light interferometer. The area of the investigated surface was $351 \mu \mathrm{m} \times 263 \mu \mathrm{m}$. Figure 2 (a) shows the resulting three-dimensional surface model. The scatter of heights along the 
investigated surface is demonstrated in Figure 2 (b). The topography of the surface with an altitude indication is shown in Figure 2 (c). On the basis of surface studies using an interferometer, it can be observed that the height of the surface does not differ by more than $1 \mathrm{~nm}$, which indicates a high uniformity of the film.

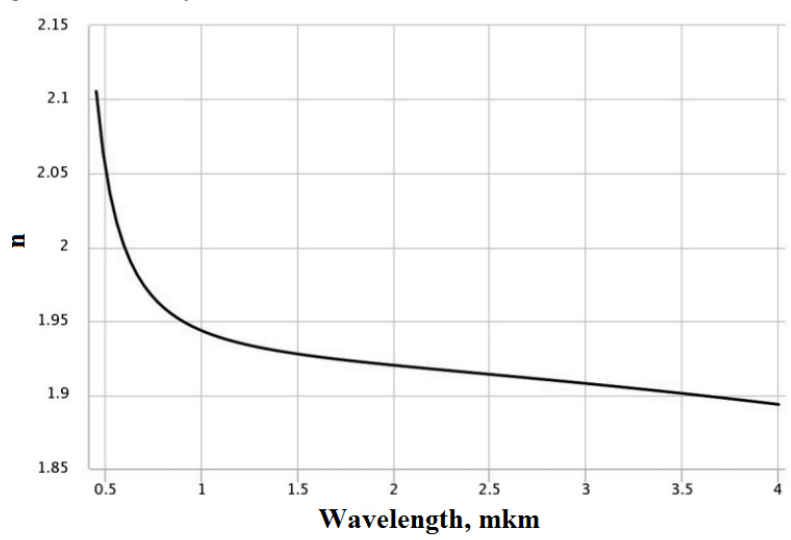

Fig. 1. The dependence of the refractive index (n) of $\mathrm{ZnO}$ on the wavelength.

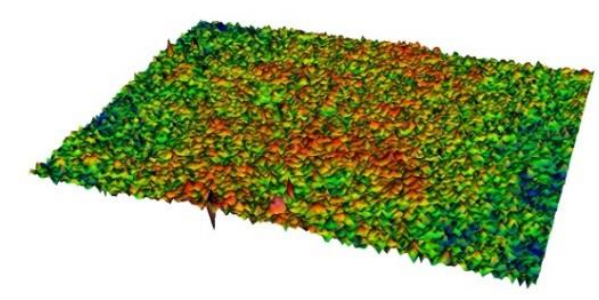

a)

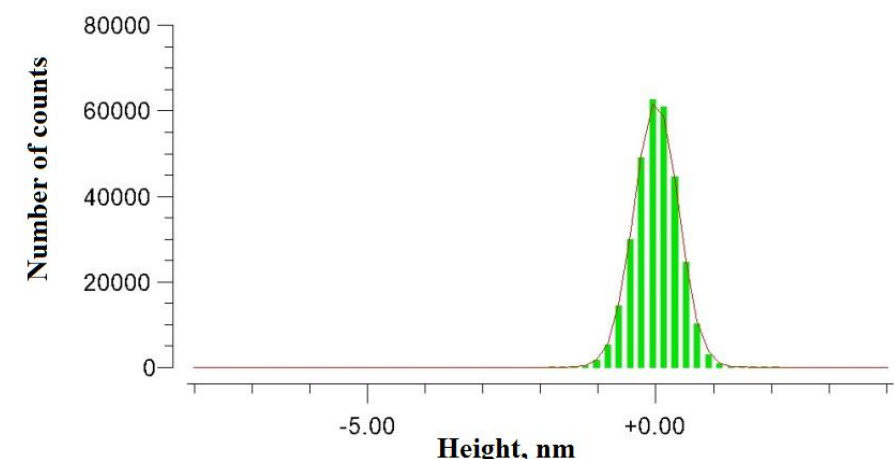

b)

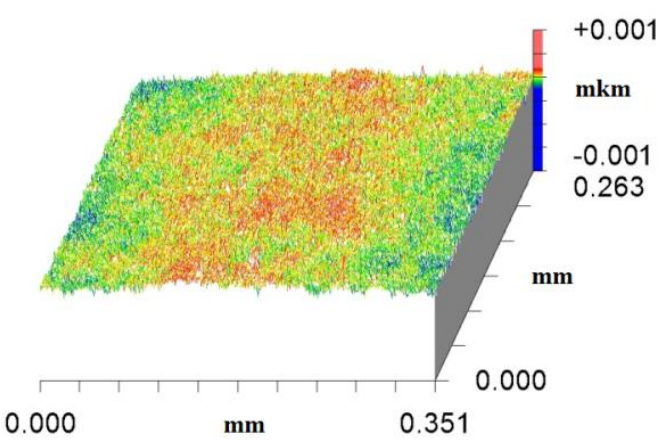

c),

Fig. 2. The surface morphology of zinc oxide ( $\mathrm{ZnO})$ film measured with the help of white light interferometer, Zygo NewView 7300 : (a) a three-dimensional model of the surface, (b) dispersion of the height of the indicator portion of the surface under study, (c) the surface topography.

\section{Conclusion}

In this work, the modernization of the magnetron sputtering unit was carried out. The deposition of $\mathrm{ZnO}$ thin film was demonstrated by using the optimized parameters of the matching device and the deposition modes.

The height of the deposited layer helped determine the deposition rate at a given mode. The layers were smooth and homogeneous which makes it possible to use $\mathrm{ZnO}$ along with other dielectric materials for the fabrication of multilayer diffractive optical elements.

Moreover, our aim is to fabricate optical filters with an alternating layers of dielectric thin films with a high and low refractive index.

\section{Acknowledgements}

This work was partially funded by the Ministry of Education and Science of the and Russian Foundation for Basic Research grant No. 16-29-11744. 


\section{References}

[1] Danilov OB, Sidorov AI. Controllable diffractive optical elements with a vanadium dioxide film. Journal of Technical Physics $1999 ;$; 69 (11): 91-96.

[2] Bykov DA, Dokolovich LL. Diffraction of an optical beam on a Bragg grating with a defect layer. Computer Optics 2014; $38(4)$ : $590-597$.

[3] Butt MA, Fomchenkov SA, Ullah A, Habib M, Ali RZ. Modeling of multylayer dielectric filters based on TiO2 / SiO2 and TiO2 / MgF2 for fluorescence microscopy imaging. Computer Optics 2016; 40(5): 674-678. DOI: 10.18287/2412-6179-2016-40-5-674-678.

[4] Butt MA, Fomchenkov SA. Thermal effect on the optical and morphological properties of TiO2 thin films obtained by annealing a Ti metal layer. Journal of the Korean Physical Society 2017; 70(2): 169-172.

[5] Paranin VD, Karpeev SV, Tukmakov KN, Volodkin BO. Tunable diffraction grating with transparent indium-tin oxide electrodes on a lithium niobate x-cut crystal. Computer Optics 2016; 40(5): 685-688. DOI: 10.18287/2412-6179-2016-40-5-685-688.

[6] Verma P, Pavelyev VS, Volodkin BO, Tukmakov KN, Reshetnikov AS, Andreeva TV, Fomchenkov SA, Khonina SN. Design, simulation, and fabrication of silicon-on-insulator mems vibratory decoupled gyroscope. Computer Optics 2016; 40(5): 668-673. DOI: 10.18287/2412-6179-2016-40-5-664-668-673.

[7] Butt MA, Fomchenkov SA. Thermal effect on the optical and morphological properties of TiO2 thin films obtained by annealing a Ti metal layer. Journal of the Korean Physical Society. 1: 607-612.

[8] Fabrication of silicon slanted grating by using modified thermal deposition technique to enhance fiber-to-chip coupling (Conference Paper) 